\title{
RESPON PERTUMBUHAN TANAMAN REKLAMASI PT NEWMONT NUSA TENGGARA TERHADAP PENGGUNAAN MULSA ORGANIK KARDUS
}

\author{
Growth Response of Reclamation Plant in PT Newmont Nusa Tenggara to the Using of Cardboard \\ Organic Mulch.
}

Iwan Hilwan $^{1 *}$ dan Meida Rosani ${ }^{2}$

(Diterima Desember 2019/Disetujui Agustus 2020)

\begin{abstract}
Plant growth determined factors such as environmental manipulation of seeds, including maintenance and pest disease prevention integrated. Intensive maintenance needs to be done especially when the plant is still young-old. Use organic mulch cardboard including part of plant maintenance to suppress weed competition with staple crops at a young age. In addition the use of mulch, organic boxes are expected to give positive influence against the growth of staple crops and chemical properties as well as land reclamation in soil biology. The results showed that organic mulching cardboard gives positive influence against the reclamation plant growth based on parameters of high and in diameter. The development of plants under around staple crops can be suppressed. Chemical properties of the soil showed improvement in some elements of the chemistry of the soil with organic mulch using cardboard. The diversity of types of makrofauna the soil around the plants with mulch treatments staple cardboard categories include being with Shannon's Diversity index value-Wiener of 1.57 while in treatment control categories include low value of 1.48 .
\end{abstract}

Keywords: cardboard mulch, plant growth, reclamation, weed

\section{PENDAHULUAN}

Kegiatan reklamasi pertambangan merupakan kegiatan pasca tambang yang harus dilaksanakan oleh perusahaan pertambangan berdasarkan Peraturan Menteri Energi dan Sumber Daya Mineral No. 7 Tahun 2014. Pertambangan adalah sebagian atau seluruh tahapan kegiatan dalam rangka penelitian, pengelolaan, dan pengusahaan mineral atau batubara yang meliputi penyelidikan umum, eksplorasi, studi kelayakan, konstruksi, penambangan, pengolahan dan pemurnian, pengangkutan dan penjualan, serta kegiatan pasca tambang (Kemenesdm 2014).

Reklamasi adalah kegiatan penataan untuk memperbaiki dan memulihkan kembali lahan serta vegetasi hutan yang rusak agar dapat berfungsi secara optimal sesuai peruntukannya (UU No. 41 Tahun 1991 tentang Kehutanan Pasal 44). Salah satu kegiatan pokok dalam reklamasi lahan pasca tambang adalah revegetasi. Revegetasi adalah usaha untuk memperbaiki dan memulihkan vegetasi yang rusak melalui kegiatan penanaman dan pemeliharaan pada lahan bekas penggunaan kawasan hutan (Kemenhut 2009). Setiadi (2006) menyatakan bahwa revegetasi adalah usaha penanaman kembali di lahan bekas tambang untuk perbaikan biodiversitas dan pemulihan estetika lanskap

\footnotetext{
${ }^{1}$ Staf Pengajar Departemen Silvikultur, Fakultas

Kehutanan dan Lingkungan Institut Pertanian Bogor

* Penulis korespondensi:

e-mail: ihilwan@yahoo.co.id

${ }^{2}$ Mahasiswa Departemen Silvikultur, Fakultas Kehutanan Institut Pertanian Bogor
}

serta komunitas tumbuhan asli secara berkelanjutan untuk mengendalikan erosi dan aliran permukaan untuk mendukung keberhasilan dari revegetasi lahan yang terganggu.

Keberhasilan revegetasi ditentukan oleh berbagai faktor diantaranya bibit yang unggul, manipulasi lingkungan termasuk pemeliharaan dan pencegahan hama penyakit terpadu. Pemeliharaan intensif sangat diperlukan terutama ketika tanaman masih dalam kondisi muda. Gulma menjadi pesaing tanaman pokok pada waktu muda. Persaingan tersebut diantaranya terhadap unsur hara, cahaya matahari, dan ruang tumbuh.

Alternatif yang digunakan untuk penanggulangan persaingan tanaman pokok dengan gulma adalah dengan pemulsaan di sekitar tanaman pokok menggunakan mulsa kardus. Pemulsaan ini diharapkan dapat memberi pengaruh positif untuk menanggulangi persaingan tanaman pokok dengan gulma, selain itu pemulsaan dengan mulsa kardus juga diharapkan dapat memperbaiki sifat fisik, kimia, dan biologi tanah. Pemulsaan telah dilaksanakan mulai Bulan Februari 2016.

Hasil pengamatan satu bulan setelah pemulsaan menunjukkan bahwa tumbuhan bawah disekitar tanaaman pokok dengan perlakuan mulsa kardus jumlah individunya lebih sedikit dibandingkan dengan tumbuhan bawah tanpa perlakuan mulsa kardus. Pertumbuhan tumbuhan bawah terus bertambah seiring berjalannya waktu, begitu juga pertumbuhan tanaman pokok. Oleh karena itu perkembangan dan pertumbuhan tumbuhan bawah dan tanaman pokok perlu diamati lebih lanjut untuk mengetahui pengaruh penggunaan mulsa kardus terhadap pertumbuhan tanaman pokok. 
Penelitian ini bertujuan untuk (1) mempelajari pengaruh penggunaan mulsa organik kardus terhadap pertumbuhan tanaman pokok, (2) mengidentifikasi perkembangan tumbuhan bawah di sekitar tanaman pokok setelah tiga bulan pemasangan mulsa, (3) mengidentifikasi pengaruh mulsa terhadap sifat kimia tanah yaitu $\mathrm{pH}$, kapasitas tukar kation (KTK), C organik, $\mathrm{N}$ total, rasio $\mathrm{C} / \mathrm{N}$, $\mathrm{P}$ tersedia, dan $\mathrm{K}$ total; serta sifat biologi tanah yaitu keanekaragaman jenis makro fauna tanah.

\section{Manfaat Penelitian}

Hasil dari penelitian ini diharapkan dapat digunakan oleh pihak pengelola sebagai bahan pertimbangan terhadap kegiatan pemeliharaan tanaman pokok di lahan reklamasi.

\section{METODE PENELITIAN}

\section{Waktu dan Lokasi}

Penelitian dilaksanakan pada bulan Mei - Juni 2016. Penelitian berupa pengambilan data primer di area reklamasi PT Newmont Nusa Tenggara Tongoloka Dump 345-405 2014.

\section{Bahan dan Alat}

Bahan yang digunakan dalam penelitian ini yaitu tegakan dengan tingkat pertumbuhan semai di area reklamasi PT Newmont Nusa Tenggara Tongoloka 2014 Dump 345-405 dan alkohol 70\%. Alat yang digunakan yaitu skop, meteran jahit, meteran gulung, trash bag, plastik spesimen, kotak spesimen, kamera digital, pita, spidol permanen, label, dan pinset.

\section{Prosedur Penelitian}

\section{Pengaruh Mulsa Organik Kardus terhadap Pertumbuhan Tanaman Pokok}

Pengambilan data pertumbuhan tanaman dilakukan terhadap tanaman dengan perlakuan mulsa kardus dan tanaman tanpa perlakuan mulsa kardus (kontrol). Ilustrasi pengambilan sampel tanaman dapat dilihat di Gambar 1. Parameter yang digunakan untuk mengetahui pertumbuhan tanaman pokok adalah dengan pengukuran

\begin{tabular}{|c|c|c|c|c|c|c|c|c|c|}
\hline $\mathbf{A}$ & $\mathbf{E}$ & $\mathbf{B}$ & $\mathbf{C}$ & $\mathbf{D}$ & $\mathbf{A}$ & $\mathbf{B}$ & $\mathbf{C}$ & $\mathbf{A}$ & $\mathbf{C}$ \\
\hline $\mathbf{a}$ & $\mathbf{b}$ & $\mathbf{d}$ & $\mathbf{b}$ & $\mathbf{e}$ & $\mathbf{c}$ & $\mathbf{a}$ & $\mathbf{b}$ & $\mathbf{c}$ & $\mathbf{d}$ \\
\hline $\mathbf{B}$ & $\mathbf{B}$ & $\mathbf{C}$ & $\mathbf{A}$ & $\mathbf{B}$ & $\mathbf{C}$ & $\mathbf{A}$ & $\mathbf{A}$ & $\mathbf{B}$ & $\mathbf{A}$ \\
\hline $\mathbf{a}$ & $\mathbf{c}$ & $\mathbf{a}$ & $\mathbf{c}$ & $\mathbf{b}$ & $\mathbf{a}$ & $\mathbf{c}$ & $\mathbf{a}$ & $\mathbf{c}$ & $\mathbf{b}$ \\
\hline $\mathbf{A}$ & $\mathbf{C}$ & $\mathbf{B}$ & $\mathbf{A}$ & $\mathbf{B}$ & $\mathbf{A}$ & $\mathbf{C}$ & $\mathbf{B}$ & $\mathbf{B}$ & $\mathbf{B}$ \\
\hline $\mathbf{a}$ & $\mathbf{a}$ & $\mathbf{b}$ & $\mathbf{a}$ & $\mathbf{c}$ & $\mathbf{a}$ & $\mathbf{c}$ & $\mathbf{c}$ & $\mathbf{a}$ & $\mathbf{c}$ \\
\hline
\end{tabular}

Keterangan :

$\mathbf{A}, \mathbf{B}, \mathbf{C}, \mathbf{D}, \mathbf{E}=$ Jenis tanaman pokok perlakuan mulsa kardus $\mathbf{a}, \mathbf{b}, \mathbf{c}, \mathbf{d}, \mathbf{e}=$ Jenis tanaman pokok kontrol $=$ Plot pengambilan data

Gambar 1 Ilustrasi pengambilan sampel tinggi dan diameter tanaman pokok. Pengukuran dilakukan terhadap 5 jenis tanaman pokok di setiap perlakuan. Setiap jenis tanaman pokok diwakili oleh 25 individu sampel sehingga jumlah total tanaman pokok sampel di dua perlakuan tersebut adalah 250 individu.

Dilakukan juga penilaian terhadap kesehatan tanaman untuk setiap individu yang diukur pertumbuhannya. Penilaian kesehatan tanaman dilakukan melalui kondisi fisik tanaman. Kondisi fisik tanaman yang diamati terbagi menjadi 3 (tiga) kriteria, yaitu tanaman sehat, kurang sehat, dan merana. Pada penelitian ini penilaian kondisi fisik tanaman ditambah menjadi empat yaitu sehat, tidak sehat, merana, dan terlilit. Kondisi terlilit ditambahkan karena kondisi lapangan yang banyak terdapat gulma dengan sifat melilit dan kondisi terlilit adalah kriteria untuk tanaman pokok yang terlilit saja tetapi masih sehat.

\section{Analisis Vegetasi Tumbuhan Bawah}

Analisis vegetasi dilakukan di sekitar tanaman pokok di dua perlakuan berbeda. Plot yang digunakan yaitu plot persegi berukuran $50 \mathrm{~cm}$ x $50 \mathrm{~cm}$ disesuaikan dengan ukuran mulsa kardus. Pengambilan data dilakukan di plot yang sama dengan pengukuran pertumbuhan tanaman pokok. Penempatan plot mengikuti tanaman pokok yang menjadi sampel seperti pada Gambar 1.

\section{Identifikasi Sifat Kimia Tanah}

1. Pengambilan sampel

Pengambilan sampel dilakukan dengan metode komposit. Sampel tanah diambil di lima titik di setiap perlakuan (Gambar 2), kemudian dikompositkan sehingga untuk setiap perlakuan terdapat satu sampel tanah. Pengambilan contoh tanah komposit adalah teknik pengambilan contoh tanah pada beberapa titik pengambilan, kemudian contoh-contoh tersebut disatukan dan dicampur/diaduk sampai merata, kemudian dilakukan analisis tanah (Suganda et al. 2002).

2. Identifikasi sifat fisik dan kimia tanah

Identifikasi sifat sifat kimia tanah yaitu $\mathrm{pH}$, KTK, $\mathrm{C}$ organik, $\mathrm{N}$ total, rasio $\mathrm{C} / \mathrm{N}$, $\mathrm{P}$ tersedia, dan $\mathrm{K}$ total dilakukankan di Laboratorium Tanah dan Tanaman SEAMEO BIOTROP (Southeast Asian Regional Centre fot Tropical Biology) Bogor.

\section{Identifikasi Sifat Biologi Tanah}

1. Penentuan plot pengamatan

Plot pengamatan dibuat pada dua perlakuan berbeda dengan jumlah plot masing - masing perlakuan sebanyak empat. Empat plot pengamatan diletakkan secara purposive sampling sehingga total plot berjumlah 8 . Tiap plot berukuran $50 \mathrm{~cm}$ x $50 \mathrm{~cm}$ dengan kedalaman $5 \mathrm{~cm}$.

2. Pengambilan makro fauna tanah

Pengambilan makro fauna tanah diambil pada serasah dan tanah. Seluruh makrofauna yang berada di dalam serasah dan di dalam bahan tanah dikumpulkan dengan hand sorting method. Makrofauna tanah yang terambil dimasukkan ke dalam tabung plastik berisi alkohol $70 \%$. 


\section{Identifikasi jenis makro fauna tanah}

Identifikasi jenis makro fauna tanah dilakukan berdasarkan sampel makrofauna yang didapatkan.

\section{Prosedur Analisis Data}

\section{Pertumbuhan Tanaman Pokok}

Perbedaan perlakuan antara kontrol dengan pemulsaan menggunakan mulsa organik kardus dianalisis menggunakan uji nonparametrik Mann Whitney. Pengujian dilakukan menggunakan Sofrware SPSS 16 (Statistical Product and Service Solutions).

\section{Analisis Vegetasi Tumbuhan Bawah}

Analisis untuk mengetahui perkembangan tumbuhan bawah dilakuka dengan menghitung Indeks Nilai Penting (INP) setiap jenis yang ditemukan. INP ini digunakan untuk menetapkan dominansi suatu jenis terhadap jenis lainnya.

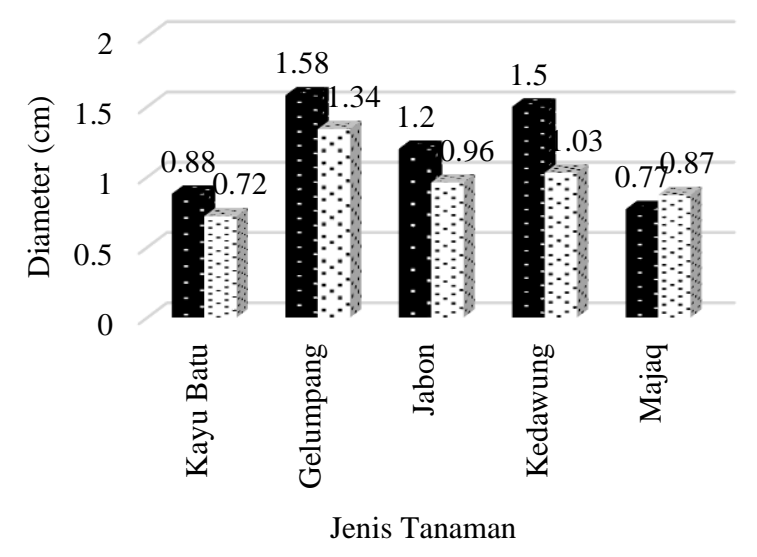

- Mulsa Kardus $\quad \because$ Kontrol

Gambar 2 Perbandingan diameter tanaman pokok

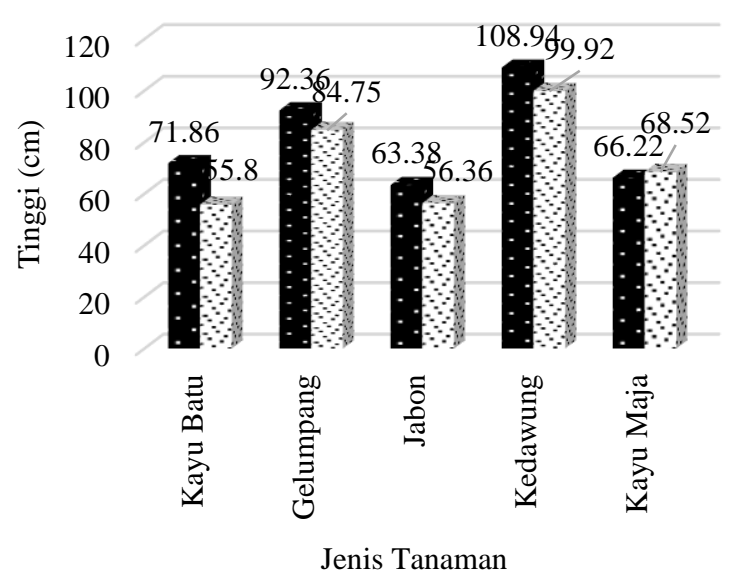

aulsa Kardus $\quad \because$ Kontrol

Gambar 3 Perbandingan tinggi tanaman pokok

\section{Keanekaragaman Makrofauna Tanah}

Analisis data dilakukan dengan menggunakan Indeks Keragaman Shannon-Wiener.

\section{HASIL DAN PEMBAHASAN}

\section{Pertumbuhan Tanaman Pokok}

Pengukuran pertumbuhan dilakukan terhadap diameter dan tinggi tanaman pokok. Tanaman pokok memiliki tahun tanam sama yaitu ditanam pada Bulan Desember 2014. Pengukuran pertumbuhan dilakukan terhadap lima jenis tanaman pokok di setiap perlakuan dengan ulangan sebanyak 25 individu untuk setiap jenis di setiap perlakuan. Jenis tanaman pokok sampel yaitu kayu batu (Alstonia stipulata) Gelumpang (Sterculia foetida), Jabon (Anthocephalus cadamba), Kedawung (Parkia timoriana), dan Majaq (Syzygium polyathum).

Perbandingan pertumbuhan tanaman di perlakuan pemulsaan dengan lokasi kontrol tersaji dalam Gambar 2 dan Gambar 3

\section{Kesehatan Tanaman Pokok}

Kesehatan tanaman pokok di dua perlakuan dapat dilihat pada Tabel 1. Tanaman pokok dengan kategori sehat di tanaman dengan perlakuan mulsa kardus lebih besar presentasenya yaitu $39.0 \%$ sedangkan tanaman kontrol $28.8 \%$. Kategori kurang sehat, merana, dan terlilit untuk tanaman pokok kontrol memiliki presentase yang lebih besar dibandingkan tanaman pokok dengan perlakuan mulsa kardus. Hal ini berarti bahwa mulsa kardus memberikan pengaruh positif terhadap kesehatan tanaman.

\section{Pertumbuhan Tumbuhan Bawah setelah Tiga Bulan Pemasangan Mulsa Kardus}

Tujuan awal pemulsaan menggunakan mulsa organik kardus adalah untuk menekan pertumbuhan gulma. Pengamatan yang dilakukan satu bulan setelah pemasangan mulsa yaitu pada Bulan Maret 2016 menunjukkan mulsa kardus dapat menekan pertumbuhan tumbuhan bawah dilihat dari jumlah individu tumbuhan bawah yang ditemukan di plot pengamatan berukuran 50 $\mathrm{cm}$ x $50 \mathrm{~cm}$ (Tabel 2). Setelah tiga bulan pemasangan mulsa kardus dilakukan kembali pengamatan untuk melihat pertumbuha tumbuhan bawah dan didapat hasil seperti pada Tabel 3 .

Berdasarkan Tabel 2 dan Tabel 3 dapat dilihat bahwa tumbuhan bawah mengalami pertumbuhan yang cukup

Tabel 1 Persentase kesehatan tanaman pokok

\begin{tabular}{lrrrr}
\hline \multirow{2}{*}{ Kesehatan } & \multicolumn{2}{c}{ Mulsa } & \multicolumn{2}{c}{ Kontrol } \\
\cline { 2 - 5 } & $\begin{array}{c}\text { Jumlah } \\
\text { Individu }\end{array}$ & $\begin{array}{c}\text { Persentase } \\
(\%)\end{array}$ & $\begin{array}{c}\text { Jumlah } \\
\text { Individu }\end{array}$ & $\begin{array}{c}\text { Persentase } \\
(\%)\end{array}$ \\
\hline Sehat & 49 & 39.00 & 36 & 28.80 \\
Tidak & 44 & 35.20 & 48 & 38.40 \\
sehat & & & & \\
Merana & 1 & 0.80 & 7 & 5.60 \\
Terlilit & 31 & 24.80 & 34 & 27.20 \\
\hline
\end{tabular}


signifikan di kedua lokasi pengamatan. Pertumbuhan tersebut harus diimbangi dengan pemeliharaan yang dapat menekan pertumbuhan tumbuhan bawah agar tumbuhan bawah tidak menjadi gulma bagi tanaman pokok. Pemasangan mulsa kardus pada awalnya mampu menekan pertumbuhan tumbuhan bawah namun pada bulan ke-tiga setelah pemasangan mulsa, mulsa kardus mulai terdekomposisi sehingga tumbuhan bawah mampu tumbuh dan berkembang dengan baik.

Stylosanthes sp. sedangkan jenis lainnya baru ditemukan saat pengamatan kali ini. Hal tersebut menunjukkan bahwa terjadi perkembangan pertumbuhan di lantai hutan. Jenis yang mendominasi di dua kali pengamatan sama yaitu jenis Leptochloa chinensis dengan INP di lokasi pemulsaan sebesar $48.82 \%$ dan INP di lokasi kontrol $66.77 \%$. Jenis ini merupakan rerumputan yang dapat tumbuh dan berkembang di lahan marginal sehingga mendominasi di lokasi pengamatan.

Centrosema sp. dapat dikategorikan sebagai gulma di lokasi pengamatan karena sifat melilitnya menyebabkan tanaman pokok tertekan, bahkan merana sehingga dikhawatirkan akan mati jika tidak dilakukan pemeliharaan. Centrosema sp. mendominasi setelah Leptochloa chinensis. Jenis ini cukup mencolok ketika pengamatan dilakukan karena memiliki sifat melilit.

\section{Sifat Kimia Tanah}

Sifat-sifat kimia tanah yang diamati pada penelitian ini adalah $\mathrm{pH}$ tanah, kapasitas tukar kation (KTK), C organik, $\mathrm{N}$ total, rasio $\mathrm{C} / \mathrm{N}$, $\mathrm{P}$ tersedia, dan $\mathrm{K}$. Nilai $\mathrm{pH}$ tanah menunjukkan tingkat kemasaman tanah. Tanah di kedua perlakuan termasuk dalam kategori agak masam berdasarkan klasifikasi Hardjowigeno (1995) karena memiliki pH antara 5.6 - 6.5. KTK tanah di kedua perlakuan termasuk dalam kategori tinggi $(25-40)$, nilai KTK di perlakuan mulsa lebih tinggi dibandingkan di perlakuan kontrol. C organik menunjukkan kandungan karbon yang terdapat di dalam tanah yang dapat diserap oleh tanaman. Tanah di dua perlakuan termasuk kategori sangat rendah kadar $\mathrm{C}$ organik karena memiliki nilai $<1.00 \%$. Kadar C organik yang normal sesuai kriteria hara tanah yaitu $2.10 \%-3.00 \%$. N total menunjukkan kandungan unsur Nitrogen yang terdapat di dalam tanah. Kandungan $\mathrm{N}$ di perlakuan mulsa kardus termasuk kategori sangat rendah karena memiliki nilai $<0.10$, sedangkan di perlakuan kontrol termasuk kategori rendah $(0.10-0.20)$. Rasio $\mathrm{C} / \mathrm{N}$ di perlakuan mulsa kardus memiliki nilai 9 sedangkan di perlakuan kontrol memiliki nilai 7. Kandungan P (fosfor tersedia) di perlakuan mulsa kardus termasuk kategori sangat tinggi (>35), sedangkan di perlakuan kontrol termasuk kategori rendah $(10-15)$.

Tabel 2 Hasil analisis vegetasi tumbuhan bawah setelah satu bulan pemasangan mulsa kardus

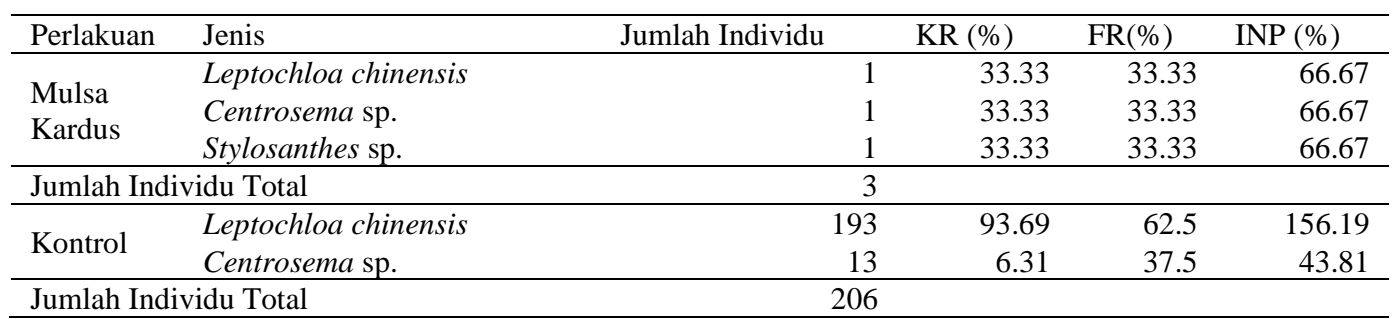

Tabel 3 Hasil analisis vegetasi tumbuhan bawah setelah tiga bulan pemasangan mulsa kardus

\begin{tabular}{|c|c|c|c|c|c|}
\hline Perlakuan & Jenis & Jumlah Individu & $\mathrm{KR}(\%)$ & $\mathrm{FR}(\%)$ & INP $(\%)$ \\
\hline \multirow{7}{*}{$\begin{array}{l}\text { Mulsa } \\
\text { Kardus }\end{array}$} & Leptochloa chinensis & 253 & 48.65 & 19.62 & 48.82 \\
\hline & Centrosema sp. & 142 & 27.30 & 48.59 & 27.72 \\
\hline & Pachyrhizus sp. & 100 & 19.23 & 23.36 & 19.43 \\
\hline & Mimosa pudica & 9 & 1.73 & 4.67 & 1.77 \\
\hline & Stylosanthes sp. & 9 & 1.73 & 1.86 & 1.74 \\
\hline & Calopogonium sp. & 6 & 1.15 & 0.93 & 1.16 \\
\hline & Desmodium rotindofolium & 1 & 0.19 & 0.93 & 0.20 \\
\hline \multicolumn{2}{|c|}{ Jumlah Individu Total } & 520 & & & \\
\hline \multirow{6}{*}{ Kontrol } & Leptochloa chinensis & 463 & 43.84 & 22.92 & 66.77 \\
\hline & Centrosema sp. & 254 & 24.05 & 36.30 & 60.35 \\
\hline & Stylosanthes sp. & 136 & 12.87 & 8.91 & 21.79 \\
\hline & Pachyrhizus sp. & 109 & 10.32 & 17.83 & 28.15 \\
\hline & Mimosa pudica & 67 & 6.34 & 8.91 & 15.26 \\
\hline & Desmodium rotindofolium & 27 & 2.55 & 5.09 & 7.65 \\
\hline \multicolumn{2}{|c|}{ Jumlah Individu Total } & 1056 & & & \\
\hline
\end{tabular}

Tabel 4 Hasil analisis tanah di sekitar tanaman pokok dengan dua perlakuan berbeda

\begin{tabular}{ccccccccc}
\hline \multirow{2}{*}{ Perlakuan } & \multicolumn{2}{c}{$\mathrm{pH}$} & \multirow{2}{K}{$\begin{array}{c}\text { KTK } \\
(\mathrm{cmol} / \mathrm{kg})\end{array}$} & $\begin{array}{c}\mathrm{C} \text { Organik } \\
(\%)\end{array}$ & $\begin{array}{c}\mathrm{N} \text { total } \\
(\%)\end{array}$ & Rasio C/N & $\begin{array}{c}\text { P tersedia } \\
(\mathrm{ppm})\end{array}$ & $\mathrm{K}(\mathrm{cmol} / \mathrm{kg})$ \\
\cline { 2 - 6 } Mulsa kardus & 6.2 & 5.7 & 34.67 & 0.59 & 0.07 & 9 & 63.9 & 0.22 \\
Kontrol & 5.8 & 5.2 & 25.49 & 0.72 & 0.10 & 7 & 13.3 & 0.03 \\
\hline
\end{tabular}

Sumber: Hasil analisis contoh tanah No 1218/TT/VI/2016 Laboratorium Tanah dan Tanaman SEAMEO BIOTROP Bogor, 2016 
Kandungan K (Kalium) tersedia di perlakuan mulsa kardus termasuk kategori rendah, sedangkan di perlakuan kontrol termasuk kategori sangat rendah $(<0,1)$ (Hardjowigeno 1995). Hasil analisis tanah di sekitar tanaman pokok dengan dua perlakuan berbeda disajikan pada Tabel 4.

\section{Kelimpahan dan Keanekaragaman Makrofauna Tanah di Lokasi Pemulsaan dan Kontrol}

Pengamatan terhadap kelimpahan makrofauna tanah dilakukan terhadap tanaman pokok dengan dua perlakuan berbeda. Kelimpahan makrofauna tanah yang ditemukan di sekitar tanaman pokok dengan perlakuan mulsa kardus dan kontrol yaitu 577 individu dan 287 individu. Kelimpahan makrofauna tanah mengacu pada jumlah individu yang ditemukan di plot pengamatan. Data kelimpahan makrofauna tanah secara lengkap disajikan pada Tabel 5. Adanya mulsa kardus dapat meningkatkan kelembaban tanah yang mendukung keberadaan makrofauna tanah dan menjadi sumber makanan bagi makrofauna tanah.

Keanekaragaman makrofauna tanah di lokasi pengamatan dapat menunjukkan perkembangan makrofauna tanah sebab lokasi pengamatan merupakan area reklamasi yang masih tergolong baru yaitu berumur 1.5 tahun. Keanekaragaman makrofauna tanah di sekitar tanaman pokok dengan perlakuan mulsa kardus termasuk kategori sedang dengan nilai Indeks Keragaman Shannon-Wiener sebesar 1.57 sedangkan di perlakuan kontrol termasuk kategori rendah dengan nilai 1.48 .

\section{Mulsa Organik}

Pengaruh mulsa kardus terhadap pertumbuhan tanaman reklamasi yang diamati pada 5 jenis tanaman berbeda menunjukkan pertumbuhan yang lebih baik pada 4 jenis tanaman berdasarkan parameter tinggi dan diameter. Jenis tanaman Kayu Batu (Alstonia stipulata), Gelumpang (Sterculia foetida), Jabon (Anthocephalus chinensis), dan Kedawung (Parkia timoriana) memiliki rata-rata pertumbuhan tanaman yang lebih tinggi di tanaman dengan perlakuan mulsa organik kardus. Tanaman pokok jenis Majaq (Syzygium polyanthum)

Tabel 5 Kelimpahan makrofauna tanah

\begin{tabular}{clclc}
\hline & \multicolumn{2}{c}{ Mulsa Kardus } & \multicolumn{2}{c}{ Kontrol } \\
\cline { 2 - 5 } No & \multicolumn{1}{c}{ Ordo } & $\begin{array}{r}\text { Jumlah } \\
\text { Individu }\end{array}$ & \multicolumn{1}{c}{ Ordo } & $\begin{array}{r}\text { Jumlah } \\
\text { Individu }\end{array}$ \\
\hline 1 & Thysanura & 64 & Thysanura & 73 \\
2 & Diplopoda & 249 & Diplopoda & 81 \\
3 & Hymenopt & 121 & Hymenopter & 101 \\
& era & & a & 3 \\
4 & Hymenopt & 90 & Hymenopter & \\
& era & & a & 8 \\
5 & Oligochaet & 29 & Oligochaeta & 14 \\
6 & Coleoptera & 3 & Coleoptera & 2 \\
7 & Coleoptera & 1 & Coleoptera & 2 \\
8 & Coleoptera & 1 & Araneae & 3 \\
9 & Coleoptera & 12 & Blatodea & \\
10 & Coleoptera & 6 & & \\
11 & Araneae & 1 & & \\
\hline
\end{tabular}

menunjukkan rata-rata pertumbuhan yang lebih baik dengan perlakuan kontrol dibandingkan perlakuan mulsa kardus. Pertumbuhan Majaq tersebut tidak sesuai dengan penyataan Sumanna (1994) yang menyatakan bahwa pemberian mulsa organik dapat meningkatkan pertumbuhan tanaman karena fungsi dari mulsa tersebut. Kondisi tanaman pokok Majaq dengan perlakuan mulsa kardus sebagian besar terlilit tumbuhan bawah akibat kondisi mulsa kardus yang terdekomposisi sehingga tidak dapat berfungsi sebagai penekan pertumbuhan tumbuhan bawah.

Dilakukan uji Mann-Whitney terhadap data tinggi dan diameter yang telah didapat di dua perlakuan. Uji Mann-Whitney dilakukan karena data tidak menyebar secara normal. Uji Mann-Whitney termasuk statistika nonparametrik, biasanya digunakan untuk melakukan analisis pada data berjenis nominal atau ordinal. Dalam praktik, tidak semua data statistik bisa diolah menggunakan metode parametrik, baik hal itu disebabkan jumlah data yang minim, distribusi data yang tidak normal, jenis data ataupun sebab lainnya. Menurut Santoso (2010) sebagai alternatif dapat digunakan berbagai metode nonparametrik, dengan dukungan software seperti SPSS memungkinkan pengguna mengolah data dan menginterpretasi output dengan mudah.

Hasil uji Mann-Whitney menunjukkan bahwa mulsa kardus berpengaruh signifikan terhadap diameter tanaman dengan nilai p-value 0.002, dikatakan signifikan jika nilai $p$-value $<0.05$. Mulsa kardus juga memberikan pengaruh signifikan terhadap tinggi tanaman dengan nilai $\mathrm{p}$-value 0.151 . Hasil tersebut menunjukkan bahwa mulsa kardus memberikan pengaruh positif terhadap pertumbuhan tanaman pokok.

Variasi pertumbuhan disebabkan oleh faktor lingkungan dan genetis sehingga sulit ditarik garis tegas, karena keduanya saling mempengaruhi lagi pula ada sifat-sifat kuat dipengaruhi susunan genetis dan ada pula yang plastis mudah berubah dengan adanya faktor lingkungan. Misalnya pertumbuhan tinggi lebih dipengaruhi oleh susunan genetis dari pada pertumbuhan diameter (Purwanto 2003).

Mulsa memberikan banyak manfaat untuk produksi tanaman melalui konservasi tanah dan air, aktivitas biologis tanah meningkat, serta perbaikan sifat fisik dan kimia tanah (Kumar dan Lal 2012). Pemberian mulsa organik akan memberikan suatu lingkungan pertumbuhan yang baik bagi tanaman karena dapat mengurangi evaporasi, mencegah penyinaran langsung sinar matahari yang berlebihan terhadap tanah serta kelembaban tanah dapat terjaga, sehingga tanaman dapat menyerap air dan unsur hara dengan baik (Subhan dalam Sumanna 1994). Mulsa kardus termasuk mulsa organik karena kardus terbuat dari bahan dasar pulp dan dapat terurai secara alami.

Kesehatan tanaman di lokasi pengamatan diamati berdasarkan kondisi fisik tanaman. Berdasarkan Peraturan Menteri Kehutanan Republik Indonesia Nomor 60 tahun 2009 tentang Pedoman Penilaian Keberhasilan Reklamasi Hutan, penilaian kesehatan tanaman dilakukan melalui kondisi fisik tanaman. Kondisi fisik tanaman yang diamati terbagi menjadi 3 (tiga) kriteria, 
yaitu tanaman sehat, kurang sehat, dan merana (Kemenhut 2009).

Berdasarkan hasil penelitian (Tabel 1) tanaman dengan perlakuan mulsa kardus memiliki presentase kesehatan tanaman lebih tinggi yaitu 39.00\% dibandingkan dengan tanaman tanpa perlakuan mulsa kardus (kontrol) dengan presentase kesehatan $28.80 \%$. Kesehatan tanaman di lokasi pengamatan dipengaruhi oleh persaingan antara tanaman pokok dengan tumbuhan bawah terutama tumbuhan bawah yang memiliki sifat merambat melilit. Persaingan antara tanaman pokok dengan tumbuhan bawah biasanya terjadi di awal kegiatan pembangunan hutan (Puslitbang Kemenhut 2012).

Tumbuhan bawah dianggap sebagai vegetasi awal yang dapat melindungi tanah sebelum adanya tanaman pokok. Di lahan bekas tambang tumbuhan bawah memiliki dampak positif diantaranya untuk menstabilkan lahan, tetapi memiliki dampak negatif yaitu dapat menjadi pesaing pertumbuhan tanaman pokok (Sheoran et al. 2010). Menurut Mansur (2013) lilitan terhadap tanaman pokok dan persaingan unsur hara dengan rumput dapat menekan pertumbuhan, bahkan pada tingkat tertentu dapat mematikan tanaman kehutanan yang ditanam.

Adanya mulsa dapat meningkatkan kandungan air tanah dengan meningkatkan perkolasi dan retensi, megurangi penguapan, serta menekan pertumbuhan gulma (Chalker 2007). Mulsa merupakan sebuah lapisan tebal yang dapat menghambat cahaya mencapai gulma (Smith dalam Hesammi dan Moghaddam 2013). Tanpa cahaya yang cukup tanaman tidak akan menghasilkan cukup klorofil untuk pertumbuhan. Benih tumbuhan bawah yang berada di bawah lapisan mulsa tidak akan tumbuh karena sinar matahari tidak dapat mencapai benih tersebut (Hesammi dan Moghaddam 2013).

Perkembangan tumbuhan bawah setelah tiga bulan pemasangan mulsa menunjukkan peningkatan baik itu dilihat dari jumlah jenis tumbuhan bawah maupun dari jumlah individu. Jumlah jenis tumbuhan bawah di lokasi pemulsaan yaitu sebanyak 7 jenis sedangkan di lokasi kontrol ditemukan 6 jenis. Jumlah individu yang ditemukan di lokasi pemulsaan yaitu 520 individu sedangkan di lokasi kontrol 1056 individu. Berdasarkan Tabel 2 dan Tabel 3 dapat dilihat bahwa tumbuhan bawah mengalami pertumbuhan yang cukup signifikan di kedua lokasi pengamatan. Pertumbuhan tersebut harus diimbangi dengan pemeliharaan yang dapat menekan perkembangan tumbuhan bawah agar tumbuhan bawah tidak menjadi gulma bagi tanaman pokok. Pemasangan mulsa kardus pada awalnya mampu menekan perkembangan tumbuhan bawah namun pada bulan ketiga setelah pemasangan mulsa kardus, mulsa mulai terdekomposisi sehingga tumbuhan bawah mampu berkembang dengan baik.

Jenis tumbuhan bawah yang ditemukan sama dengan pengamatan awal yaitu Centrosema sp., Leptochloa chinensis, dan Stylosanthes sp. sedangkan jenis lainnya baru ditemukan saat pengamatan kali ini. Hal tersebut menunjukkan bahwa terjadi perkembangan pertumbuhan di lantai hutan. Jenis yang mendominasi di dua kali pengamatan sama yaitu jenis Leptochloa chinensis dengan INP di lokasi pemulsaan sebesar $48.82 \%$ dan
INP di lokasi kontrol $66.77 \%$. Jenis ini merupakan rerumputan yang dapat tumbuh dan berkembang di lahan marginal sehingga mendominasi di lokasi pengamatan. Centrosema sp. dapat dikategorikan sebagai gulma di lokasi pengamatan karena sifat melilitnya menyebabkan tanaman pokok tertekan, bahkan merana sehingga dikhawatirkan akan mati jika tidak dilakukan pemeliharaan. Centrosema sp. mendominasi setelah Leptochloa chinensis. Jenis ini cukup mencolok ketika pengamatan dilakukan karena memiliki sifat melilit. Tumbuhan bawah atau tanaman penutup tanah akan menjadi gulma (tanaman pengganggu) atau sebagai kompetitor tanaman pokok yang mengganggu dalam beberapa cara seperti secara langsung sebagai kompetitor untuk cahaya, air, unsur hara, dan naungan. Beberapa jenis gulma juga memiliki sifat merambat, melilit, atau mencekik tanaman pokok. Gulma merambat akan menaungi dan menambah beban berat sehingga bibit bengkok atau rebah (Mansur 2013).

Pengaruh mulsa kardus dalam menekan pertumbuhan tumbuhan bawah untuk persaingan antara tanaman pokok dengan tumbuhan bawah dapat dilihat pada Tabel 2 dan 3. Jumlah individu dan jumlah jenis tumbuhan bawah di sekitar tanaman pokok dengan perlakuan mulsa kardus setelah satu bulan pengamatan lebih sedikit dibandingkan setelah 3 bulan pemasangan mulsa kardus. Hasil tersebut menunjukkan bahwa mulsa kardus dapat menekan pertumbuhan tumbuhan bawah dalam jangka waktu tertentu sehingga diperlukan pemeliharaan berupa pembaharuan mulsa kardus. Berdasarkan pengamatan yang dilakukan di satu bulan dan tiga bulan setelah pemasangan mulsa kardus, pembaharuan mulsa kardus sebaiknya dilakukan setiap tiga bulan untuk mencegah pertumbuhan tumbuhan bawah di sekitar tanaman pokok yang dapat menekan pertumbuhan tanaman pokok.

Perlakuan tanpa pemulsaan (kontrol) dapat dijadikan acuan untuk melihat perkembangan tumbuhan bawah di area reklamasi Tongoloka 2014 Dump 345 - 405 PT Newmont Nusa Tenggara. Kerapatan tumbuhan bawah setelah satu bulan pemulsaan adalah 1648000 individu per hektar, sedangkan kerapatan tumbuhan bawah setelah tiga bulan pemulsaan adalah 337920 individu per hektar. Hal tersebut diduga karena Leptochloa chinensis menjadi tumbuhan bawah pioneer yang pertama kali tumbuh (Tabel 2) kemudian tumbuhan bawah jenis lain seperti Centrocema sp. dan Pachyrhizus sp. tumbuh lalu menghambat perkembangan Leptochloa chinensis sehingga Leptochloa chinensis tidak terlalu pesat perkembangannya.

Perkembangan tumbuhan bawah di sekitar tanaman pokok dengan perlakuan mulsa kardus terjadi karena terdekomposisinya mulsa kardus sehingga area sekitar tanaman pokok terbuka. Pertumbuhan tumbuhan bawah setelah satu bulan dan tiga bulan pemasangan mulsa kardus yaitu 24000 individu per hektar dan 166400 individu per hektar (Tabel 2 dan 3). Perbedaan kerapatan per hektar tersebut menunjukkan bahwa mulsa kardus dapat menekan pertumbuhan tumbuhan bawah. Hal ini sesuai dengan pernyataan Lakitan (1995) dalam Marliah et al. (2011) yang menyatakan bahwa mulsa dapat menghambat laju pertumbuhan gulma. Pertumbuhan tumbuhan bawah dapat menjadi penyebab pertumbuhan 
tanaman pokok terhambat, seperti terjadi pada tanaman pokok jenis Majaq (Syzygium polyanthum) dengan perlakuan mulsa kardus.

Menurut Subowo et al. (1990) penggunaan mulsa organik akan membantu mengurangi erosi, mempertahankan kelembaban tanah, mengendalikan $\mathrm{pH}$, memperbaiki drainase, mengurangi pemadatan tanah, meningkatkan kapasitas pertukaran ion, dan meningkatkan aktivitas biologi tanah. Perbedaan nilai kapasitas tukar kation (KTK) di sekitar tanaman perlakuan mulsa organik kardus dengan perlakuan kontrol menunjukkan perbedaan kandungan bahan organik yang terdapat pada tanah. Tabel 4 menunjukkan bahwa nilai KTK di sekitar tanaman perlakuan mulsa kardus lebih tinggi dibandingkan di perlakuan kontrol. Hal tersebut diduga karena adanya bahan organik dari kardus yang terurai di dalam tanah. Perbedaan nilai KTK tersebut sesuai dengan hasil penelitian Harsono (2012) yang menunjukkan bahwa nilai KTK untuk perlakuan mulsa organik lebih tinggi dibandingkan perlakuan kontrol.

Hasil analisis tanah menunjukkan rasio $\mathrm{C} / \mathrm{N}$ di perlakuan mulsa kardus memiliki nilai yang lebih besar yaitu 9 dibandingkan dengan di perlakuan kontrol yaitu 7. Menurut Hairiah et al. (2000), kecepatan pelapukan mulsa organik tergantung perbandingan karbon dan nitrogen dari bahan tersebut. Bahan yang memiliki $\mathrm{C} / \mathrm{N}$ rasio kecil akan mengalami proses pelapukan yang lebih cepat bila dibanding bahan organik yang memiliki $\mathrm{C} / \mathrm{N}$ rasio lebih besar. Pernyataan tersebut menunjukkan bahwa bahan organik yang berada di sekitar tanaman pokok perlakuan kontrol yaitu berupa serasah tumbuhan bawah yang terdapat di lapangan proses pelapukannya lebih cepat dibandingkan bahan organik di sekitar tanaman pokok perlakuan mulsa kardus yaitu kardus. Kardus lebih sulit terurai dibandingkan serasah tumbuhan bawah karena kardus terbuat dari bahan organik berupa pulp kayu yang sudah dipadatkan dan direkatkan. Willy dan Yahya (2001) dalam Gultom (2011) menyatakan bahwa kardus berasal dari bahan baku yang dapat didaur ulang, dan karena penambahan unsur lain (perekat) berbasis air; material ini layak untuk diproses daur ulang dan bersifat biodegradable (dapat diurai oleh tanah).

Menurut Harsono (2012), pemberian mulsa organik dapat meningkatkan kadar C organik tanah dibandingkan kondisi tanah alami sebelum percobaan. Pernyataan tersebut tidak sesuai dengan hasil yang didapat pada penelitian ini. Penggunaan mulsa organik kardus belum memberikan kandungan bahan organik berupa $\mathrm{C}$ organik yang lebih baik, karena nilai rasio $\mathrm{C} / \mathrm{N}$ di perlakuan mulsa kardus belum menunjukkan bahwa kardus dapat terurai dengan cepat serta kondisi mulsa kardus di lapangan belum terdekomposisi secara menyeluruh. Meningkatnya kadar $\mathrm{N}$ total tanah dengan perlakuan mulsa organik membuktikan bahwa bahan organik tanaman sebagai sumber utama $\mathrm{N}$ tanah setelah bahan organik mengalami dekomposisi (Harsono 2012). Pernyataan tersebut sesuai dengan penelitian yang membuktikan bahwa bahan organik tanaman sebagai sumber utama $\mathrm{N}$ tanah setelah bahan organik mengalami dekomposisi.
Nilai rasio $\mathrm{C} / \mathrm{N}$, $\mathrm{C}$ organik, dan $\mathrm{N}$ total di perlakuan mulsa kardus lebih rendah dibandingkan perlakuan kontrol. Hal ini diduga karena komposisi bahan organik kardus lebih sulit terdekomposisi dibandingkan bahan organik tanaman yang terdapat di perlakuan kontrol. $\mathrm{N}$ tersedia di udara dengan kadar $78 \%$ sehingga kebutuhan $\mathrm{N}$ dapat dipenuhi. Meskipun demikian, penggunaan mulsa kardus perlu dipertahankan untuk menekan perkembangan tumbuhan bawah di sekitar tanaman pokok agar tidak terjadi persaingan dengan tumbuhan bawah. Tanaman pokok di perlakuan mulsa kardus tidak menunjukkan gejala kekurangan unsur hara $\mathrm{N}$ yang dominan seperti daun menguning, mengering bahkan rontok.

Perlakuan mulsa organik kardus memberikan kadar $\mathrm{P}$ (fosfor) tersedia sebesar $63.9 \mathrm{ppm}$ jauh lebih tinggi dibandingkan $\mathrm{P}$ tersedia perlakuan kontrol dengan nilai $13.3 \mathrm{ppm}$. Hasil proses penguraian dan mineralisasi bahan organik selain melepaskan fosfor anorganik juga melepaskan senyawa P organik yang dapat dimanfaatkan oleh tanaman (Harsono 2012). Fungsi dari unsur P adalah mempercepat pertumbuhan akar dan mempercepat serta memperkuat tanaman muda menjadi tanaman dewasa. Nilai unsur $\mathrm{P}$ yang tinggi di perlakuan mulsa kardus sangat mendukung pertumbuhan tanaman pokok.

Hara K (Kalium) dalam tanah bersifat mobile, mudah terlindi atau mudah terangkut oleh aliran air ke tempat lain (Foth dan Ellis 1988 dalam Ispandi 2003). Pelindian hara $\mathrm{K}$ tersebut dapat dihambat dengan pemberian mulsa organik karena tanah dengan mulsa organik mampu meningkatkan kapasitas tukar kation yang menambah kemampuan tanah dalam menahan unsur-unsur hara, termasuk K. Pernyataan tersebut sesuai dengan hasil yang terdapat pada Tabel 3 yang menunjukkan bahwa nilai K dan KTK di perlakuan mulsa kardus lebih tinggi dibandingkan dengan perlakuan kontrol. Unsur hara $\mathrm{K}$ berperan sebagai pengatur proses fisiologi tanaman seperti fotosintetis, akumulasi, translokasi, transportasi karbohidrat, membuka menutupnya stomata, atau mengatur distribusi air dalam jaringan dan sel. Kekurangan unsur ini menyebabkan daun seperti terbakar dan akhirnya gugur.

Fungsi lain mulsa khususnya mulsa organik yaitu untuk mendukung keberadaan fauna tanah. Mulsa yang telah menjadi bahan organik merupakan sumber energi yang menyebabkan aktivitas dan populasi fauna tanah meningkat (Soedarsono 1982 dalam Damaik 2010). Beberapa penelitian menunjukkan bahwa tanah-tanah terdegradasi pada umumnya menunjukkan penurunan keanekaragaman dan biomassa makrofauna tanah (Giller et al. 1997 dalam Sugiyarto et al. 2005). Makrofauna tanah memiliki arti penting pada ekosistem terestrial. Pada ekosistem pertanian, makarofauna tanah berperan dalam pemeliharaan sifat fisika, kimia dan biologi tanah, terutama sebagai dekomposer dan soil engineer sehingga dapat meningkatkan produktivitas tanaman budidaya. Selain itu berbagai jenis makrofauna tanah juga berperan sebagai hama, sedangkan sebagian lainnya berperan sebagai predator sehingga erat kaitannya dengan sistem pengendalian hayati (Killham 1994 dalam Sugiyarto et al. 2005).

Terdapat perbedaan kelimpahan makrofauna tanah di kedua perlakuan. Kelimpahan individu di lokasi 
pemulsaan lebih besar dibandingkan di lokasi kontrol yaitu 577 individu berbanding 287 individu. Hal ini diduga karena mulsa organik kardus memberi pengaruh positif terhadap kelimpahan makrofauna tanah. Adanya mulsa kardus dapat meningkatkan kelembaban tanah yang mendukung keberadaan makrofauna tanah dan menjadi sumber makanan bagi makrofauna tanah.

Lahan reklamasi PT Newmont Nusa Tenggara termasuk lahan dengan tanah terdegradasi akibat adanya pemindahan dan penyusunan kembali tanah pucuk karena kegiatan pertambangan. Keanekaragaman makrofauna tanah dipengaruhi secara signifikan oleh tutupan lahan dan kondisi tanah suatu area (Baoming el al. 2014). Keanekaragaman jenis makrofauna tanah di sekitar tanaman pokok dengan perlakuan mulsa kardus tergolong sedang, sedangkan keanekaragaman jenis di sekitar tanaman pokok tanpa perlakuan tergolong rendah. Kondisi lapangan untuk dua perlakuan mulsa kardus dan kontrol adalah sama, namun di perlakuan mulsa kardus menunjukkan keanekaragaman makrofauna tanah termasuk sedang. Penggolongan tersebut menunjukkan perlakuan mulsa kardus memberikan dampak positif terhadap keanekaragaman makrofauna tanah.

\section{SIMPULAN DAN SARAN}

\section{Simpulan}

Mulsa kardus memberikan pengaruh signifikan terhadap pertumbuhan tanaman pokok. Nilai p-value pengaruh penggunaan mulsa kardus terhadap diameter tanaman pokok yaitu 0.002 sedangkan nilai p-value pengaruh penggunaan mulsa kardus terhadap tinggi tanaman pokok yaitu 0.151 . Perkembangan tumbuhan bawah di sekitar tanaman pokok dengan perlakuan mulsa kardus mengalami peningkatan dan didominasi oleh Leptochloa chinensis. Sifat kimia tanah di perlakuan mulsa kardus lebih mendukung untuk pertumbuhan tanaman pokok dibandingkan dengan perlakuan kontrol. Keanekaragaman jenis makrofauna tanah di sekitar tanaman pokok dengan perlakuan mulsa kardus termasuk dalam kategori sedang menurut Indeks Keragaman Shannon Wiener dan di sekitar tanaman pokok kontrol termasuk kategori rendah. Ordo makrofauna tanah yang mendominasi di sekitar tanaman pokok dengan perlakuan mulsa kardus adalah Diplopoda, sedangkan ordo yang mendominasi di sekitar tanaman pokok dengan perlakuan kontrol adalah Hymenoptera.

\section{Saran}

PT Newmont Nusa Tenggara disarankan untuk menggunakan mulsa kardus dalam program pemeliharaan tanaman pokok usia muda, serta penggantian mulsa kardus sebaiknya dilakukan setiap tiga bulan.

\section{DAFTAR PUSTAKA}

Adinda. 2012. Evaluasi pertumbuhan pohon di lokasi revegetasi lahan pasca tambang PT Vale Indonesia
Tbk, Sorowako, Sulawesi Selatan. [skripsi]. Bogor (ID): Institut Pertanian Bogor.

Baoming GE, Daizhen Z, Boping T, Chunlin Z. 2014. Effect of land cover biodiversity and composition of a soil macrofauna community in reclaimed coastal area at Yancheng, China. Turk J Zool 38: $229-233$.

Chalker L. 2007. Impact of Mulches on Landscape plants and the environmen. Environ Hort 25(4): 239 249.

Damaik BSD. 2010. Pengaruh penggunaan mulsa jerami padi terhadap beberapa sifat fisik tanah dan laju infiltrasi pada latosol Dramaga (studi pada tanaman kacang tanah). [skripsi]. Program Studi Manajemen Sumber Daya Lahan, Departemen Ilmu Tanah dan Sumber Daya Lahan, Fakultas Pertanian, Institut Pertanian Bogor.

Gultom AT. 2011. Karakteristik papan semen dari limbah kertas kardus dengan penambahan katalis natrium silikat. Universitas Sumatera Utara. http://repository.usu.ac.id/handle/123456789/266 89. Diakses tanggal 14 Mei 2016

Hairiah K,Widianto, Noordwijk, Cadisch G. 2000. Pengelolaan Tanah Masam Secara Biologi. ICRAF. Bogor.

Harsono P. 2012. Mulsa organik: Pengaruhnya terhadap lingkungan mikro, sifaat kimia tanah, dan keragaman cabai merah di tanah Vertisol Sukoharjo pada musim kemarau. J. Hort. Indonesia 3(1): $35-41$.

Hesammi E, Moghaddam PR 2013. Library research, some strategis for weed management in organic farming. IJFAS 2(4): $96-101$.

Hardjowigeno. 1995. Ilmu Tanah. Jakarta (ID): Akademika

Ispandi A. 2003. Pemupukan P, K dan waktu pemberian pupuk $\mathrm{K}$ pada tanaman ubi kayu di lahan kering Vertisol.Ilmu Pertanian 10(2): 35 - 50.

[Kemenesdm] Kementerian ESDM. 2014. Peraturan Menteri ESDM Nomor 7 tahun 2014 tentang Pelaksanaan Reklamasi dan Pasca Tambang pada Kegiatan Usaha Pertambangan Mineral dan Batu Bara. Jakarta (ID): Kementerian ESDM.

[Kemenhut] Kementerian Kehutanan. 2009. Peraturan Menteri Kehutanan Republik Indonesia Nomor: P.60/Menhut-II/2009 tentang Pedoman Penilaian Keberhasilan Reklamasi Hutan. Jakarta (ID): Kementerian Kehutanan.

Kumar SD, Lal BR. 2012. Effect of mulching on crop production under rainfed condition. Ijrec 2: 8 20.

Mansur I. 2013. Teknik Silvikultur untuk Reklamasi Lahan Bekas Tambang. Bogor (ID): SEAMEO BIOTROP.

Marliah A, Nurhayati, Susilawati D. 2011. Pengaruh pemberian pupuk organik dan jenis mulsa organik terhadap pertumbuhan dan hasil Kedelai (Glycine max (L.) Merrill). Floratek 6(2):192-201.

Pemerintah Republik Indonesia. 1999. Undang-Undang Republik Indonesia Nomor 41 Tahun 1999 tentang Kehutanan. Jakarta (ID): Sekretariat Negara. 
Purwanto RH. 2003. Model pertumbuhan tinggi dan diameter batang tanaman Jati pola management Regime III di KPH Madiun. Kajian Aspek Bio Fisik PHJO. Jurnal Pengelolaan Hutan Jati Optimal (PJHO). Kerjasama Fakultas Kehutanan Universitas Gadjah Mada Yogyakarta dengan Direksi Perum Perhutani Jakarta.

[PTNNT] PT Newmont Nusa Tenggara. 2015. Laporan Reklamasi tahun 2015. (Tidak dipublikasikan).

[Puslitbang Kemenhut] Pusat Penelitian dan Pengembangan Peningkatan Produktivitas Hutan. 2012. Mulsa daun kering: Pengendalian gulma dan penyubut tanah di hutan tanaman. Bogor(ID): Puslitbang Peningkatan Produktivitas Hutan.

Santoso S. 2010. Statistik Multivariat. Jakarta (ID): PT Gramedia.

Setiadi Y. 2006. Bahan Kuliah Ekologi Restorasi. Program Studi Ilmu Pengetahuan Kehutanan, Sekolah Pasca Sarjana, Institut Pertanian Bogor. (Tidak dipublikasikan).

Sheoran V, Sheroran AS, Poonia P. 2010. Soil reclamation of abandoned mine land by revegetation. Soil, Sediment and Water 3(2): Article 13.
Subowo J, Subaga, dan M Sujadi. 1990. Pengaruh bahan organik terhadap pencucian hara tanah Ultisol Rangkasbitung, Jawa Barat. Pemberitaan Penelitian Tanah dan Pupuk 9: 26-31.

Sumanna. 1994. Pengaruh dosis fosfat dan mulsa terhadap pertumbuhan dan hasil kubis (Brassica oleraceae var. Cavitata $L, C v$, Gloria Ocena. Bul Panel. Hort 27(4):80-90.

Suganda H, Rachman A, Sutono. 2002. Petunjuk pengambilan contoh tanah. Balai Penelitian Tanah Bogor. http://balittanah.litbang.perta nian.go.id/ind/dokum entasi/lainnya/NOMOR\%2002.pdf. Diakses tanggal 14 Mei 2016.

Sugiyarto, Efendi M, Mahajoeno E, Sugiti Y, Handayanto E, Agustina L. 2005. Preferensi berbagai jenis makrofauna tanah terhadap sisa bahan organik tanaman pada intesitas cahaya yang berbeda. Biodiversitas 7(4) : 96-100.

Wahyudi. 2011. Pertumbuhan tanaman dan tegakan tinggal pada Sistem TPTI Intensif. [disertasi]. Bogor (ID): Institut Pertanian Bogor. 